\title{
Glue masquerading as a catheter: Retrieval of embolized vertebroplasty cement
}

\author{
Meena Rohini Narayanan, Ray Matthews \\ Keck School of Medicine, University of Southern California, Los Angeles, California, United States of America
}

Received: February 4, 2018

DOI: $10.5430 /$ crim.v5n2p14

Accepted: March 26, 2018

Online Published: April 11, 2018

URL: https://doi.org/10.5430/crim.v5n2p14

\begin{abstract}
Identification of foreign body objects may be difficult based on imaging characteristics. History is essential to making a diagnosis. Cement leakage is a common complication of percutaneous vertebroplasty and the optimal management for cement embolism remains unknown. This report presents a case of a 72-year-old female with asymptomatic pulmonary cement embolism, which was partially retrieved via a percutaneous endovascular approach.
\end{abstract}

Key Words: Pulmonary embolism, Bone cement, Vertebroplasty, Endovascular retrieval

\section{INTRODUCTION}

Vertebroplasty is a minimally invasive procedure used to treat vertebral compression fractures. During the procedure, polymethylmethacylate (PMMA) is injected into the vertebral body to improve pain and restore vertebral height. Although a relatively safe procedure, pulmonary cement embolism is a known complication, with incidence reported from $2 \%$ to $26 \% .^{[1,2]}$ The diagnosis may not be made immediately but instead weeks, months or years later. We present a case of a 72-year-old female with asymptomatic pulmonary cement embolism, which was partially retrieved via a percutaneous endovascular approach.

\section{Case presentation}

A 72-year-old female with history of orthotopic liver transplant, end stage renal disease on hemodialysis via permacath, cerebrovascular accident, subdural hematoma, compression fractures status post vertebroplasty four months prior at outside institution, underwent transcatheter aortic valve replacement (TAVR). On physical examination, her blood pressure was $127 / 44 \mathrm{mmHg}$, heart rate of 90 beats/min, respiratory rate of $20 \mathrm{breaths} / \mathrm{min}$. Chest radiograph showed a long, coiled tubular radiopaque density in the left pulmonary artery that was not seen previously (see Figure 1). A chest computed tomography was performed as part of her TAVR and revealed a curvilinear foreign body, with an appearance of a wire or possible catheter, in the left pulmonary artery extending into left upper lobar branches, and a separate $7 \mathrm{~mm}$ linear radiodensity in the left upper lobe (see Figure 2). Upon retaking of her history, she recalled no symptoms of chest pain or dyspnea. Due to her history of hospitalizations at other institutions and the appearance of the foreign object on imaging, there was concern of catheter embolization and the decision was made for percutaneous removal. The right common femoral vein was cannulated with a 14 French sheath. A balloon wedge pressure catheter was advanced into the left main pulmonary artery and a pulmonary angiogram was performed. Using a renal double curve (RDC) guide catheter

\footnotetext{
*Correspondence: Meena Rohini Narayanan; Email: Meena.Narayanan@med.usc.edu; Address: Keck School of Medicine, University of Southern California, Los Angeles, California, United States of America.
} 
(Cordis, Miami Lakes, FL) and a $25 \mathrm{~mm}$ Amplatz goose-neck snare (ev3, Plymouth, MN), we were able to grasp the radiolucent structure, that we thought was a catheter. However, it fractured, and a portion of the foreign body was removed (see Figure 3). At this point, it became apparent that it was tightly adherent to the pulmonary arterial wall. The decision was made not to remove the remaining fragments, due to potential risk for rupture. Given the apparent benign effect of this glue in the pulmonary artery, surgical removal was not warranted. Anticoagulation for retained foreign body was considered. Due to the chronicity of the bone cement and its incorporation into the arterial wall, we surmised that anticoagulation would not be necessary since occlusion of the left pulmonary branch would be unlikely. In addition, patient was already on dual antiplatelet therapy due to recent TAVR. Since the procedure was done fluoroscopically and patient was stable, we thought follow up imaging was not warranted. She was discharged the following day and has been seen in clinic with no complaints.

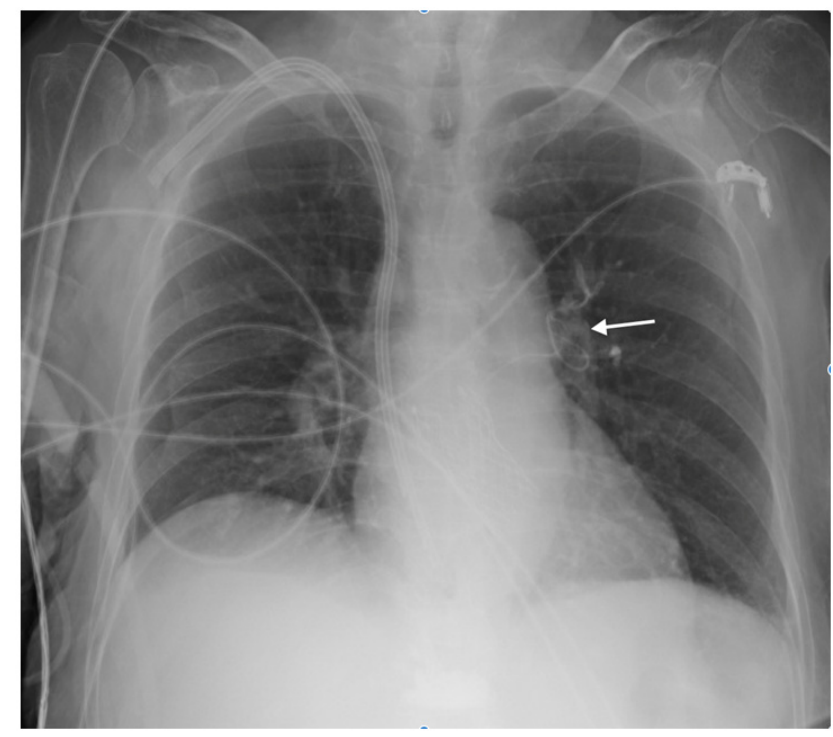

Figure 1. Chest radiography showing a long coiled, tubular radiopaque density in the left pulmonary artery (white arrow)

\section{Discussion}

Cement leakage is a known complication following vertebroplasty. In a study that performed computed tomography following percutaneous vertebroplasty, cement extravasation was high at $81 \% .^{[3]}$ Factors that influence leakage into the intravascular space include the volume of PMMA injected, the degree of viscosity of the cement, or the application of too much pressure during injection. ${ }^{[3,4]}$ When cement leaks into perivertebral veins it can enter the azygos system into the inferior vena cava entering the pulmonary vasculature. PaPublished by Sciedu Press tients may be asymptomatic or manifest clinically with fever, dyspnea, tachycardia, chest pain, hemoptysis or hemodynamic instability. In addition to pulmonary embolism, bone cement causing cardiac perforation, valvular abnormalities and paradoxical cerebral embolism have been described. ${ }^{[5]}$

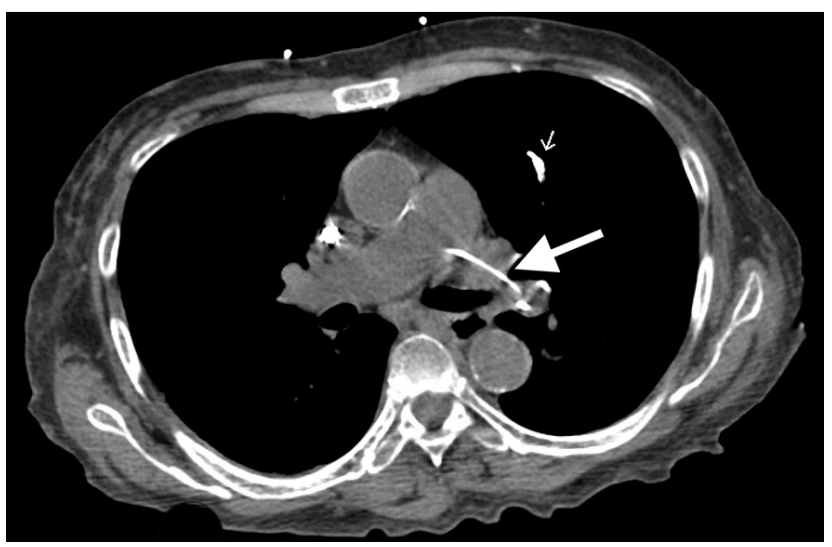

Figure 2. Chest computed tomography revealed curvilinear foreign body, with an appearance of a wire in the left pulmonary artery extending into left upper lobar branches (thick arrow), and a separate $7 \mathrm{~mm}$ linear radiodensity in the left upper lobe (thin arrow)

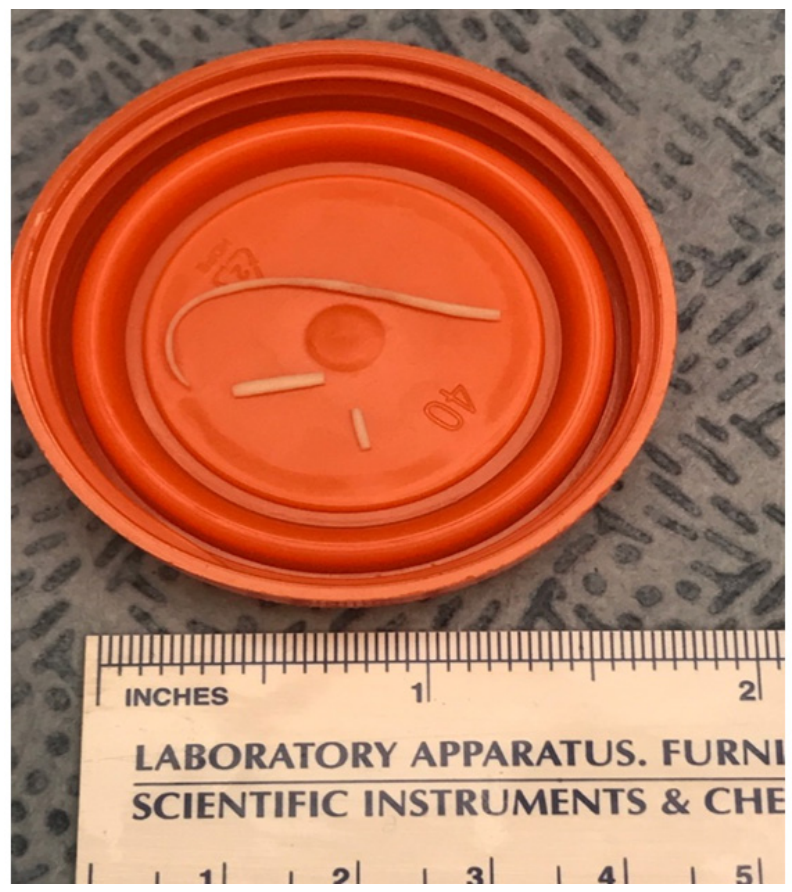

Figure 3. Gross specimen of bone cement

Due to variable incidence of pulmonary embolism, some studies have recommended routine radiographs within 24 hours of procedure for screening. ${ }^{[4,6,7]}$ Various approaches in the treatment of bone cement embolism have been described, depending on the location of the cement and the 
severity of symptoms. Options include conservative management with or without anticoagulation, endovascular retrieval, and open-heart surgery. Asymptomatic cement embolism has been reported and managed without anticoagulation and no evidence of adverse outcomes. ${ }^{[2]}$ The rationale for anticoagulation is to prevent thrombus formation on the foreign body until the it endothelizes. ${ }^{[8]}$ The optimal duration of treatment has not been defined. One case report presented evidence of thrombus attached to bone cement retrieved from the right atrium nearly five years post vertebroplasty. ${ }^{[9]}$ Endovascular or surgical removal is indicated in patients with evidence of cardiac bone cement embolism and hemodynamic compromise. Features favoring percutaneous removal include fragments that are small and linear. ${ }^{[10]}$ However, it is important to acknowledge possible complications such as further fragmentation of bone cement causing distal embolism.

Most of the prior case reports demonstrate globular densities in the lung fields rather than the linear structures seen in our case. The cement likely slowly extruded from the needle while intravascular and formed these linear structures, which were mistaken for catheter radiographically.

\section{Conclusion}

History is critical in determining the etiology of the foreign body. Given her history of prior central venous catheters, exact etiology could not be determined without retrieval of the object. This case emphasizes the importance of having high suspicion for cement embolism in patients who have a cardiac or pulmonary foreign body with a history of vertebroplasty. Long-term sequelae are not well known in these patients and optimal management is unclear. A decision to intervene has to balance the risks and benefits of removal versus conservative therapy.

\section{Conflicts of Interest Disclosure}

The authors declare no conflicts of interest.

\section{REFERENCES}

[1] Venmans A, Lohle PN, van Rooij WJ, et al. Frequency and outcome of pulmonary polymethylmethacrylate embolism during percutaneous vertebroplasty. AJNR Am J Neuroradiol. 2008; 29(10): 1983-1985. PMid:18719030. https://doi.org/10.3174/ajnr .A1269

[2] Venmans A, Klazen CA, Lohle PN, et al. Percutaneous vertebroplasty and pulmonary cement embolism: results from VERTOS II. Am J Neuroradiol. 2010 Sep; 31(8): 1451-3. PMid:20488908. https://doi.org/10.3174/ajnr.A2127

[3] Schmidt R, Cakir B, Mattes T, et al. Cement leakage during vertebroplasty: an underestimated problem? Eur Spine J. 2005 Jun; 14(5): 466-73. PMid:15690210. https ://doi.org/10.1007/s0 0586-004-0839-5

[4] Krueger A, Bliemel C, Zettl R, et al. Management of pulmonary cement embolism after percutaneous vertebroplasty and kyphoplasty: a systematic review of the literature. Eur Spine J. 2009 Sep; 18(9): 1257-65. PMid:19575243. https ://doi.org/10.1007/s00586 -009-1073-y

[5] Shridhar P, Chen Y, Khalil R, et al. A Review of PMMA Bone Cement and Intra-Cardiac Embolism. Materials (Basel). 2016 Oct 6; 9(10). PMid:28773942. https://doi.org/10.3390/ma9100821
[6] Geraci G, Lo Iacono G, Lo Nigro C, et al. Asymptomatic Bone Cement Pulmonary Embolism after Vertebroplasty: Case Report and Literature Review. Case Rep Surg. 2013; 2013: 591432. PMid:23738182. https://doi.org/10.1155/2013/591432

[7] Cianciulli TF, Mc Loughlin DE, Morita LA, et al. Bone cement cardiac and pulmonary embolism. Echocardiography. 2017 Aug; 34(8): 1239-1241. PMid:28573824. https://doi.org/10.1111/echo .13580

[8] Minelli C, Kikuta A, Tsud N, et al. A micro-fluidic study of whole blood behaviour on PMMA topographical nanostructures. J Nanobiotechnol. 2008; 6: 3. PMid:18284677. https://doi.org/ $10.1186 / 1477-3155-6-3$

[9] Lim KJ, Yoon SZ, Jeon YS, et al. An intraatrial thrombus and pulmonary thromboembolism as a late complication of percutaneous vertebroplasty. Anesth Analg. 2007 Apr; 104(4): 924-6. PMid:17377108. https ://doi.org/10.1213/01.ane.0000256974.84535.7a

[10] Lamparello NA, Jaswani V, DeSousa K, et al. Percutaneous Retrieval of an Embolized Kyphoplasty Cement Fragment From the Pulmonary Artery: A Case Report and Literature Review. J Radiol Case Rep. 2016 Jul 31; 10(7): 40-47. PMid:27761188. https : //doi.org/10.3941/jrcr.v10i7.2806 